\title{
IMAGENS DO TEMPO NOS MEANDROS DA MEMÓRIA: POR UMA ETNOGRAFIA DA DURAÇÃO
}

\section{Ana Luiza Carvalho da Rocha e Cornelia Eckert}

O processo de desencaixe "espaço-tempo" que as novas tecnologias da informática têm proposto para os lugares da memória no corpo da sociedade contemporânea, ao configurar as relações homem e cosmos em redes mundiais de comunicação, tem provocado nas ciências humanas a necessidade de se aprofundarem novas formas de entendimento das estruturas espaço-temporais que configuram a magia dos mundos virtuais.

Para se enfrentar esse e outros desafios, cada vez mais o que se coloca é a relevância não apenas de se refletir sobre as diferentes modalidades de tecnologias de pensamento (oralidade, escrita, redes digitais) empregadas pelas sociedades humanas para liberar a memória de seu suporte material ${ }^{1}$ até atingir sua expressão recente em redes eletrônicas e digitais, mas, principalmente, de se indagar a respeito das operações e proposições através das quais as ciências humanas têm enfrentado, até o momento, o conhecimento da matéria do tempo e suas cadeias operatórias.

Assim, antes de se insistir na polêmica sempre enriquecedora acerca da existência propriamente dita do fenômeno da memória, este artigo tem por intenção um convite especial ao seu leitor. Ou seja, um mergulho nos meandros das imagens do tempo que configuram o conteúdo dinâmico da imaginação criadora de diferentes autores que foram desafiados a compreender o fenômeno da memória no sentido de resgatar-se aí uma "epistemologia do conhecimento" de sua existência ${ }^{2}$.

Em especial isso exigirá do leitor o seu afastamento gradativo de uma posição epistemológica que aposta no caráter de ilusão, em geral psicológica, atribuído às operações do pensamento humano que sustentam os jogos da memória, no sentido de reduzir a imagem aos fenômenos da consciência, minimizando o lugar da imaginação criadora como elemento formal do pensamento humano ou tornando-a apenas um resíduo psicológico e "material" da consciência.

Nessa linha de investigação, o leitor é desafiado a compartilhar, com as autoras, de um conhecimento ainda em processo de gestação, adotando a fragilidade de um pensamento que

\footnotetext{
${ }^{1}$ Uma referência nesta abordagem é a obra de A LEROI-GOURHAN, Le geste et la parole. Vol I e II. Paris, Albin Michel, 1964.

${ }^{2}$ Segue-se aqui alguns desafios propostos por Jean PIAGET na obra Sabedoria e Ilusões da Filosofia, São Paulo, Editora Abril, 1978, p.128
} 
se empenha na compreensão dos fenômenos da memória na perspectiva da flexibilidade da inteligência humana em arranjar sentido ao mundo quando confrontada com o caráter perecível de suas ações.

A proposta parece ser, até certo ponto, simples. Trata-se de um convite ao leitor para que ele abandone as antíteses clássicas - organização viva e matéria, instinto e inteligência, tempo e espaço, vida interior, ação e linguagem - tais como as que aparecem nas obras de Bergson, Husserl e Sartre, para submergi-las num outro espaço de problemas, a saber: a convergência de tais instâncias entre si, por encaixes ou equivalência simples ou complexas, na unidade entre pensamento simbólico (da ordem das imagens) e pensamento conceitual. Isto é, instâncias que apresentam "interseções segundo combinações” diversas que se solidarizam, gerando a unidade do pensamento e de suas expressões simbólicas, topos a partir do qual pode se pensar a estruturação simbólica da memória.

Em particular, cabe uma primeira decifração de ordem particular: a relevância de se indagar sobre a magnitude dos golpes administrados pelo bergsonismo à idéia de um continuum da consciência quando o pensamento filosófico do Ocidente moderno permanecia conferindo à imagem e à imaginação funções meramente reguladoras da existência. Por outro, trata-se aqui, sem dúvida, de uma crítica à doutrina bergsonista que atribui à imagem um papel secundário, espécie de "totalidade mnésica da consciência", pela forma como ela aparece no interior do par antitético, vida e matéria. Acima de tudo, cabe salientar, que mesmo refém das armadilhas da psicologia clássica a obra de Henry Bergson, Matéria e Memória (concebida em 1896), permanece, ainda nos dias de hoje, a fonte de inspiração para muitos estudos antropológicos sobre memória ${ }^{3}$.

Assim, pretende-se instaurar, neste artigo, outras vias para o estudo da memória, na linha de uma fenomenologia da imaginação que não a introspecção bergsonista ou o monismo do cogito sartriano, onde a imagem aparece sempre cumprindo um papel suspeito de regressão, "estreitamente empirista, tanto mais quanto se pretende que ela esteja separada de um pensamento puramente lógico",4.

\footnotetext{
${ }^{3}$ A referência central deste artigo é, sem dúvida, a obra de H. BERGSON, Matéria e Memória, S.P. Martins Fontes, 1990, além de outras tais como "A Evolução criadora", In; Coleção Os Pensadores, São Paulo, Abril Cultural, 1978 e Durée et Simultanéité, esta última citada por PIAGET, 1978.

${ }^{4}$ Um belo exemplo de crítica à duração bergsoniana é a obra de G. DURAND, Les structures anthropologiques de l'imaginaire, Paris, Dunod, 1984, em particular a Introdução e o Capítulo II, do Livro Terceiro, "Éléments pour une fantastique transcendantale", autor da frase acima citada.
} 


\section{Memória, contestação às antíteses bergsonianas}

“É preciso que a reflexão construa tempo ao redor de um acontecimento, no
próprio instante em que o acontecimento se produz, para que reencontremos
esse acontecimento na recordação do tempo desaparecido. Sem a razão, a
memória é incompleta e ineficaz”. BACHELARD. 1988: 48-49.

Com efeito, a abordagem subjetivista de H. Bergson (1859-1941) e seu método introspectivo é referência primordial nos estudos sobre temporalidade e memória. Seguidor da linhagem do idealismo, para esse autor, as questões relativas ao sujeito e ao objeto, a sua distinção e união, devem ser postas em função do tempo e não do espaço.

Criticando a posição kantiana que negligencia o estudo da duração em detrimento do estudo do espaço e do tempo como construção a priori do entendimento e da sensibilidade, o bergsonismo questiona, de modo original, a anterioridade lógica, e em parte cronológica, de tais formas de juízos sintéticos. Segundo o autor de Ensaios sobre os dados imediatos da consciência (1889), A Evolução Criadora (1907) e Duração e Simultaneidade (1922), o tempo possui uma mais-valia psicológica sobre o espaço, neste sentido, minimiza-se o espaço em proveito da intuição da temporalidade. Para o autor, nossa duração, e uma certa participação sentida, vivida de nosso círculo material a essa duração interior são fatos da experiência. Desta forma, tempos "atribuídos", "fictícios", imaginados, calculados etc. aparecem em oposição a um único tempo real, o do observador "vivo e consciente".

Ironicamente, a crítica do privilégio fenomenológico do tempo em Kant arrastou o bergsonismo a sofrer, posteriormente, uma crítica do ontologismo da duração uma vez que a todo o sistema de referência, no qual estão associadas as durações vividas, nada se poderia atribuir fisicamente. Segundo a metafísica bergsoniana, o único tempo real é o tempo vivido, os tempos relativos (dependentes do meio e do ambiente onde o vivido humano se deixa ver) são meras aparências. Deste modo, existem duas formas de memórias teoricamente diferentes e independentes, uma sob a forma de imagem-hábito (eu superficial) e outra sob a forma de imagem-lembrança (eu profundo), das quais uma imagina e a outra repete, sendo que "a segunda pode substituir a primeira e freqüentemente até dar a ilusão dela” (BERGSON. 1990: 63).

Contra até mesmo a teoria geral da relatividade e a hipótese eisteniana dos tempos múltiplos, diversamente ritmados, relativos aos diferentes observadores, o bergsonismo vai afirmar uma duração que não possui propriedade métrica nem espacial, embora suscetível de dilatação ou de contração, segundo seu conteúdo, e onde o tempo passado sobrevive sob duas formas distintas, em mecanismos motores (imagem - cérebro - ação) e em lembranças 
independentes 5 ignorando que o tempo supõe velocidade, "a dos processos externos, percebidos ou observados, ou a dos processos internos da atividade mental" 6 .

No contexto da duração bergsoniana, a antítese da duração vivida e do espaço físico faz com que este autor derive daí sua tese central segundo a qual o tempo, sendo invenção, nada mais é que construção contínua de seu conteúdo. Nesta perspectiva, "o tempo é invenção ou não é absolutamente nada", daí resultando o fato de a duração vivida ter a propriedade, portanto, de não ser nem métrica, nem espacializada, ela desenvolver-se-ia numa velocidade que não é "nem nula nem infinita", o que acaba, paradoxalmente, por reduzir sua dimensão do fenômeno temporal ${ }^{7}$.

Evidentemente, na época em que foi concebida a obra Matéria e Memória, mecanicismo, organicismo ou vitalismo eram alternativas clássicas para os estudos sobre a memória, apresentando-se tal fenômeno como "uma inadaptação congênita da inteligência humana às realidades vitais" $"$.

Submerso na antítese entre vida e matéria, o tempo bergsoniano reserva à imagem, pura e simplesmente, um papel de "contadora de histórias" que não se reporta ao passado, "a menos que seja no passado que efetivamente eu vá buscá-la"9. Neste sentido, uma lembrança, à medida que se atualiza num tempo espacializado, tendendo a viver numa imagem, torna-se, por assim dizer, esvaziada de seu conteúdo.

Seguindo-se o princípio da duração bergsoniana, resta, pois o confronto da subjetividade pura (o espírito) e a pura exterioridade (a matéria). No plano da subjetividade pura, encontra-se o fenômeno da memória e da duração, no outro, o da pura exterioridade, a percepção.

Uma vez que a duração é continuidade imediata e profunda, julgamento positivo e afirmativo que afirma um pensamento liberado da vida, ela não pode romper-se senão superficialmente no exterior através da linguagem que a pretende descrever. Depreende-se daí que a inteligência humana é inapta para compreender a vida, adaptando-se ao espaço e à matéria inorganizada, somente em seus aspectos estáticos e ao descontínuo. Em decorrência, a

\footnotetext{
${ }^{5}$ Sobre o assunto ver as reflexões de J. PIAGET, 1978., p.131. Neste sentido, ver as análises das duas memórias, memória - hábito e memória-imagem, segundo BERGSON, (1990), e as críticas a elas dirigidas por BOSI, 1987 e BORELLI, 1992. Além de PIAGET, 1978, pp.128-133.

${ }^{6}$ Sobre o assunto, ver as reflexões de PIAGET, 1978:131.

${ }^{7}$ Cf. PIAGET, 1978, p.131, citando Bergson. Segundo o autor, "o tempo supõe, pois a velocidade, a dos processos externos percebidos e observados, ou a dos processos internos da atividade mental, e esse é um primeiro ponto essencial que o estudo psicogenético do tempo parece revelar". Da mesma forma, ver os comentários de G. BACHELARD, 1989, pp. 1-25. A respeito da psicologia da plenitude em Bergson.

${ }^{8}$ Novamente utilizam-se aqui os comentários contundentes de PIAGET.1978:131, sobre a afirmação do bersgsonismo a respeito da "intuição como único modo de conhecimento adaptado à vida.“

${ }^{9}$ Cf. G. DURAND, 1984.
} 
memória aparece como um fio contínuo que se tece em decorrência à oposição entre a matéria e a vida. Ou seja, a memória e a imagem, ao lado da duração e do espírito, opõem-se à inteligência e à matéria, ao lado do espaço (BOSI, 1987:15).

Certamente, em sua obra Matéria e Memória, Bergson ultrapassa seu próprio esquematismo ao relacionar a memória ao reino da imaginação, apesar de atrelá-la à atenção receptiva da vida. Assim, "é a memória que colore a imaginação de resídios a priori"10, pois "é dos elementos sensório-motores da ação presente que a lembrança retira o calor que the confere vida e é do presente que parte o apelo ao qual a lembrança responde" (BERGSON, 1990:125).

No pensamento bergsoniano, portanto, a inteligência humana só conhece adequadamente a matéria e o espaço na condição de instinto, na forma de intuição, único modo de conhecimento adaptado à vida ${ }^{11}$. Do ponto de vista epistemológico, ao assimilar a memória a uma intuição da duração e separar a representação da consciência, o bergsonismo minimiza o papel da inteligência a favor do instinto prolongado da intuição mnésica ou fabuladora $^{12}$. $\mathrm{O}$ argumento bergsoniano reduz a inteligência à representação em imagem, tornando-a efetivamente estática, inapta a apreender o contínuo, reconstituindo o contínuo no descontínuo, num processo análogo ao procedimento cinematográfico, resultado da forma dos objetos aos quais se aplica.

Semelhante proposição é frágil quando se pensa que a existência de operações inteligentes de conhecimento do mundo tem por objeto as transformações, e não somente da ação sobre a matéria, resultado das coordenações de operações lógicas e dramáticas que são independentes da natureza dos objetos visados.

Diferentemente do que o bergsonismo defende, a duração não é um fenômeno que surge de uma intuição do tempo, ela é o resultado do movimento e da construção produtiva da vida, gerada a partir de esquemas de pensamento singulares. Neste sentido, a conceituação do fenômeno temporal, as condições epistemológicas para a sua compreensão, supõe a presença da velocidade das transformações dos processos externos, ainda que percebidos, vividos ou

\footnotetext{
${ }^{10}$ Referência aos comentários de DURAND, 1984:16, sobre o aprisionamento do pensamento de Bergson ao associacionismo que norteava a psicologia clássica.

11 Segundo BORELLI, 1992, a noção de imagem em Bergson está diretamente ligada aos significados do "perceber" e do "intuir", os quais, por sua vez, se articulam às dimensões de temporalidade e de captação da memó ria.

${ }^{12}$ Cf. as críticas de G. DURAND, 1984:.466-467, ao bergsonismo onde " la memóire serait l’acte de résistance de la durée à la matière purement spatiale et de l'esprit s'opposant à l'intelligence et à la matière du côté de l'espace". Da mesma forma, ver a respeito os comentários de J. PIAGET, 1978:132, para quem "seria errôneo fechar-se na alternativa da continuidade ou da descontinuidade apresentada em termos lineares, como se a inteligência, uma vez desencadeada, prosseguisse em linha reta, num único e mesmo plano."
} 
observados, tanto quanto a dos processos internos, referidos à subjetivação dos processos externos e que se apresentam como o resultado da atividade inteligente do pensamento humano. A memória, encerrando os movimentos do pensamento é, assim, o fruto de uma construção produtiva e criadora de conhecimento; ela é a expressão das estruturas dinâmicas da inteligência.

Segundo Piaget (1978:132), se a passagem da vida é um desenrolar histórico que supõe uma contínua "invenção" temporal, a vida é, por sua vez, uma invenção espacial com base numa incrível diversidade das formas. Logo, a memória não é cega aos processos da vida, ela manifesta operações de pensamento complexas, auto-reguladoras e auto-corretivas dos processos de transformação aos quais a matéria acha-se submetida, conduzidas reflexivamente, e sujeitas ao devir do pensamento. Portanto, o que constitui a duração e rege os fenômenos da memória é a presença de uma métrica singular produzida pela inteligência humana capaz de fazer operar uma seriação dos acontecimentos segundo uma ordem de sucessão a partir dos encaixes dos intervalos de espaço-tempo nos termos de uma $\operatorname{ordenação~}^{13}$.

Neste ponto, se confrontado à teoria geral da relatividade eisteniana, poder-se-ia objetar, na contemporaneidade mais que na época de seus escritos, que Bergson opera numa escala limitada do tratamento do tempo e do espaço, concebendo-os dentro de sistemas fechados ao reservar à duração os fenômenos da consciência e a vida em suas relações antitéticas com a matéria.

Adotando-se escalas superiores (a relatividade) ou inferiores (microfísica) longe do "edifício aparentemente imutável da mecânica clássica e da física dos princípios" "14, questões postas pela transformação radical da física com a teoria geral da relatividade, cai por terra a tese da descontinuidade entre vida e matéria, e mais, desmente-se a déia bergsoniana da "inadaptação congênita da inteligência"15.

Ora, a inteligência precede a ação e a linguagem, e não somente a ação e a linguagem agindo sobre a matéria. Neste ponto, a memória aplica-se às coordenações gerais da linguagem dos símbolos culturais e da lógica de proposições que englobam as ações humanas,

\footnotetext{
${ }^{13}$ O uso da metáfora da música por PIAGET, 1978, e BACHELARD, 1989. É revelador, pois permite a ambos os autores traçar um quadro aproximativo da forma como a matéria se faz presente na regularidade da freqüência de suas ondulações.

${ }^{14}$ Cf. PIA GET, 1978, p.130.

15 Conforme PIAGET, 1978:132, “... a evolução da vida é um desenrolar histórico que supõe uma contínua invenção temporal (sem dúvida mesmo com períodos de aceleração e de diminuição). Mas a vida é na mesma proporção invenção espacial, pois a incrível diversidade das formas supõe uma espantosa combinatória geométrica...”.
} 
independente da natureza dos objetos por ela visados ${ }^{16}$. Contradizendo, portanto, as antíteses bergsonianas, a inteligência humana, imersa no plano da imaginação criadora, constrói e reconstrói a matéria de forma ininterrupta, não-linear, por equilibrações sucessivas e reversíveis dos intervalos e dos instantes vividos, através de restruturações de operações de pensamento e construções sucessivas em níveis diferentes de aproximação com o conteúdo das experiências vivida e com variações consideráveis entre $\mathrm{si}^{17}$.

Segundo o postulado da intuição bergsoniana, a memória é ao mesmo tempo, "tomada de posse" da experiência espaço-temporal humana e "garantia da verdade" para o sujeito que a vive. Encapsulada numa espécie de antidestino, a duração ontológica bergsoniana que daí se origina é, ela própria, impensável ou, se for pensada, deixa de ser duração ${ }^{18}$.

\title{
2. Memória, a reconciliação entre a consciência do real e a contínua invenção temporal
}

\author{
"Para durarmos, é preciso então que confiemos em ritmos, ou seja, em sistemas \\ de instantes. Os acontecimentos excepcionais devem encontrar ressonâncias em \\ nós para marcar-nos profundamente." BACHELARD, 1989, p.9.
}

Para adotar o novo paradigma para os estudos acerca da memória torna-se relevante retomar aqui a tese central segundo a qual a própria continuidade do pensamento humano acerca do mundo nada mais é que um fenômeno tributário da continuidade de uma substância temporal que envolve o eterno ato de conhecer e apropriar-se do mundo. Assim, em particular para o caso dos estudos de memória, o próprio processo de construção do pensamento a respeito do tempo é aliado do fenômeno que pretende conhecer, gerando uma situação epistemológica peculiar. Afastando-se de quaisquer antíteses, portanto, é a partir de uma poética do pensamento e dos arranjos estéticos de suas formas que se pretende aqui mergulhar nas imagens do tempo que compõem os meandros da compreensão do fenômeno temporal, sem esquecer que é nos insondáveis jogos da inteligência humana, em sua pretensão de decifrar o absoluto, que se tece o exercício da memória.

De forma paradoxal, é na fragilidade dos caracteres essenciais do tempo bergsoniano -

\footnotetext{
${ }^{16}$ Conforme BACHELARD, 1988, p.9: "Desta frase banal - 'a vida é harmonia' -, ousaríamos então, finalmente, fazer uma verdade. Sem harmonia, sem dialética regulada, sem ritmo, nenhuma vida, nenhum pensamento pode ser estável e seguro: o repouso é uma vibração feliz".

17 Conforme BOSI, 1987, p. 16. “... falta à duração bergsoniana uma tematização e uma reflexão sobre os sujeitos que lembram, as relações entre os sujeitos e as coisas lembradas, os nexos interpessoais, enfim, ... falta, a rigor, um tratamento da memória como fenômeno social", onde fatos e julgamentos de um viver coletivo e social são acordados à noção de memória por seus sucessores, fazendo intervir quadros condicionantes de teor social ou cultural.

${ }^{18}$ Neste ponto, precisamente, G. DURAND, 1989 p. 272 à 280, questiona-se se Bergson, ao chamar duração "o ser da consciência", não teria entendido subrepticiamente este verbo durar na acepção mais trivial que lhe dá o senso comum, ou seja, originada da expressão desde que dure, ou seja, desde que permaneça, que fique.
} 
a tese de que a memória é um conhecimento metafísico sui generis, irredutível à razão e em que a intuição procederia como fenômeno singular através do qual o conhecimento humano atingiria diretamente as realidades próprias à vida, isto é, a duração - que se resgata a magnitude do fenômeno da memória e da duração como fabricações intelectuais, produtos da inteligência humana que se conduz reflexivamente no mundo, ou seja, produtos da imaginação criadora.

Nada melhor do que evocar a dialética do ser na duração para se problematizar, inicialmente, a diversidade temporal do conhecimento adaptado à vida, cada qual seguindo um ritmo apropriado, de acordo com um ponto de vista particular.

Para se compreender o próprio fenômeno intratemporal que constitui a duração da matéria, joga-se com os seus aspectos de descontinuidade qualitativa (encadeamentos de seus ritmos) e quantitativa (intensidade, força e comprimento), cuja vibração rítmica regular permite à vida travestir-se em continuidade substancial. Sem dúvida, a duração bachelardiana não recusa a microfísica como a duração bergsoniana, ao contrário, absorve-a empregando um conceito mais sutil de matéria, isto é, matéria referida ao mundo vibrante e múltiplo dos átomos.

Diferentemente do bergsonismo, a duração bachelardiana é aqui nossa guia e nossa mestra uma vez que por seu intermédio, vida e matéria dialogam sem cessar. Segundo Bachelard anunciava já nos anos 50, basta que se desmaterializem um pouco as inquietudes pessoais com o tempo para que se possa ver o próprio tempo ondular. Não se trata mais de operar com a locução bergsoniana "durar no tempo", mas de substituí-la por outra, "permanecer no espaço", já que os jogos da memória referem-se aos trabalhos da imaginação criadora humana que desejam "materializar o tempo". (BACHELARD: 1989:32)

A matéria que se reconcilia com a vida é aqui tratada não como unidade essencial; ela não está disponível a olho nu e nem se encontra à disposição da experiência ordinária dos fenômenos vividos. Nos termos da duração bachelardiana, a matéria e a vida não se traduzem na simples oposição de sujeito e objeto, elas se reconciliam no movimento de troca incessante entre ambos e, na ausência de um, ainda está lá, automaticamente, a presença do outro ${ }^{19}$.

Atendendo-se à idéia de que o tempo é hesitação assim como a continuidade substancial da matéria só intervém tardiamente, a compreensão da duração bachelardiana

\footnotetext{
19 As teses bachelardianas em torno do fenômeno da duração encontram inúmeros pontos de ressonância nos estudos na área da epistemologia genética firmados por J.PIAGET sobre o nascimento da inteligência e a formação do símbolo na criança, além dos clássicos trabalhos sobre as operações de pensamento que configuram as noções de espaço e tempo como construções produtivas e criadoras das estruturas configuram as noções de espaço e tempo como construções produtivas e criadoras das estruturas dinâmicas do conhecimento humano.
} 
exige do estudioso da memória uma singular atenção à vacuidade e à hesitação tanto da matéria quanto da vida, exigindo-lhe uma recusa da idéia ingênua da plenitude do mundo das coisas, posto que a idéia da continuidade do tempo não é um dado em si mesmo, mas uma obra.

Opondo-se ao bergsonismo segundo o qual "pensar o tempo é enquadrar a vida", a perspectiva da duração bachelardiana, em convergência à crítica piagetiana, considera que pensar o tempo "não é tirar da vida uma aparência particular, que se captaria de modo tanto mais claro quanto mais se tiver vivido". Ao contrário, pensar o tempo é quase fatalmente "propor que se viva de outro modo, que se retifique antes de tudo a vida e em seguida que se a enriqueça". Ou seja, a meditação temporal demonstra a flexibilidade da inteligência humana face às construções sucessivas da matéria ${ }^{20}$.

No corpo das teses piagetianas e bachelardianas, o esquema da análise temporal da memória torna-se, para o investigador, uma ação complexa, adotando este o ponto de vista de um arqueólogo da vida humana ${ }^{21}$, uma vez que a duração se constrói através de diferentes níveis de operações simbólicas e cognitivas, cuja coerência de arranjos permite que memória funcione como uma estrutura de conhecimento que prepara e mede a justa causalidade psicológica e biológica humana e cuja unidade da matéria resulta da adesão global do ser a um caráter afirmativo da vida contra sua dispersão.

Em particular, para o caso do pensamento bachelardiano, a memória é um fenômeno que se realiza a partir de decisões do sujeito humano no tempo, precedida de hesitação, no interior de uma ondulação dialética em que o ser busca a consecução de uma ordem às ações vividas. Longe de uma intuição de homoge neidade global como aparece no bergsonismo, a duração bachelardiana põe em evidência os conflitos dos instantes, dos ritmos sincrônicos que configuram o tecido temporal.

Através da idéia da continuidade e da sucessão temporal no bojo da descontinuidade, onde o tempo revela-se hesitação, a dialética da duração bachelardiana provoca o leitor no entendimento das lacunas do tempo como condição de seu ato de consolidação em duração. Lacunas infinitamente reconduzidas à liberdade interpretativa dos sujeitos das ardenações temporais ao ultrapassar o domínio da experiência da vida humana tanto física quanto psicológica. Dimensão cognitiva da duração que a tese piagetiana busca realçar quando lhe

\footnotetext{
${ }^{20}$ BACHELARD, 1989, p. 76, “toutes les durées psychologiques, clairemente figurées dans des convictions raisonées, se constituent ainse, à la faveur 'une hétérogénéite de la forme et du contenu, à la feveur d'une loi rationelle sans cesse confirmée par une expérience."

${ }^{21}$ Aqui, as obras de Proust, Le Temps retrouvé e Du côté de chez Swann, ambas da Editora Gallimard, podem servir de inspiração.
} 
confere, de forma indireta, as dimensões da formação das operações de regulação e de equilibração, "que é, sem dúvida, o mais central dos processos biológicos", e de "autoregulação ou auto-correção mental, que constitui a lógica" (PIAGET, 1978:134).

Se o tempo é vibração e hesitação, por sua feição lacunar, e a vida é movimento e construção produtiva, criadora de estruturas dinâmicas, toda a análise temporal deve ultrapassar uma simples tradução desta oscilação dos instantes em falhas do tempo, sem portar aí nenhuma restruturação conceptual.

Isto é, uma análise da matéria sutil do tempo conduz a uma rythmanalyse ${ }^{22}$ e reclama uma reflexão acerca das ondulações e dos ritmos dos tempos vividos e dos tempos pensados, dos tempos intransitivos e dos tempos do mundo, buscando-se reter o momento singular em que a matéria do tempo traduz em raios ondulatórios lembranças e reminiscências cujos feixes de ondas se transformam reciprocamente em matéria.

Ou seja, coerente com um princípio da física contemporânea, a memória e a duração estão, ambas, no plano de uma análise temporal que considera a matéria e suas radiações, não uma matéria congelada no espaço, numa duração uniforme e inerte, indiferente ao tempo. Em sua estrutura ondulatória, cuja regularidade de freqüência lhe garante força de existência, a matéria se movimenta sem se dispersar, sendo que, através do pensamento, atinge um acordo temporal no interior do desacordo rítmico que constitui a própria vida ${ }^{23}$. Assim, se a matéria alcança a duração é somente porque ela atinge sucessivos graus de equilibração no interior de um tempo que vibra, pelo e no ritmo de sua vibração .

Assim, ao lado da duração pelas coisas, e não nas coisas, há a duração de um pensamento que investiga - "O que permanece? O que é que dura?", sinalizando-se, então, que permanece "apenas aquilo que tem razões para recomeçar". Na perspectiva bachelardiana, o tempo pensado é tempo vivido em estado nascente, ou seja, “o pensamento é sempre, em alguns aspectos, a tentativa ou o esboço de uma vida nova, uma tentativa de viver de outro modo, de viver mais ou até mesmo", finalmente, "uma vontade de ultrapassar a vida" (BACHELARD, 1989:79 e 1988:76).

A vida e a matéria se perdem e nos perdem, numa fragmentação incessante de instantes e estados. Entretanto, através da linguagem e da ação, fazendo concordar a

\footnotetext{
22 Segundo BACHELARD, 1988, p.133: "A ritmanálise procura em toda parte ocasiões para ritmos. Ela nos previne, assim, sobre o perigo que há em viver no contratempo, desconhecendo a necessidade fundamental das dialéticas temporais".

${ }^{23}$ Referência aos comentários de BACHELARD, 1989: 130 à 135, onde o autor, referindo-se as relações entre a matéria e o tempo, afirma ser "le rythme régulier qui apparaît sous forme d'attribut matériel determiné", isto é, "l’aspect matériel est la confusion réalisée".
} 
descontinuidade de suas ações e experiências no mundo, o sujeito humano interliga o mundo inteligível ao mundo sensível sem que consiga voltar as suas costas a função simbólica dos esquemas de pensamento que favoreceram sua reconstituição.

Para se empreender uma análise temporal, portanto, torna-se necessária uma verdadeira prudência metodológica, nos termos da poética bachelardiana, de "uma metafísica da poeira": um estudo dos arranjos conferidos às ordenações temporais vividas e representadas, cada vez menores e invisíveis, concebendo-as no decorrer da dissolução do tempo, numa série de rupturas e onde a matéria das ações passadas se desenvolve e se manifesta sob a forma de ritmos, os quais conservam sua substância.

\section{Depois do jogo de idéias...}

Inspirados nas inquietações bachelardianas e piagetianas e adotando-as para revisitar os estudos sobre memória social e coletiva nos termos empregados pela matriz antropológica $^{24}$, tais estudos, finalmente, deveriam ter por centro de suas preocupações a realização de uma etnografia da duração ${ }^{25}$.

Contrariamente ao que se processa usualmente, ou seja, uma etnografia da lembrança do passado, o estudo da etnografia da duração aceita como suposto que a matéria das lembranças ou reminiscências de um tempo vivido adquire uma substância somente se ela se "temporaliza" sob forma de ondulações do próprio ato que encerra o tempo pensado. Tais ondulações rítmicas, com as quais opera a inteligência humana face às falhas do tempo, é que são as responsáveis pela propagação da memória, onde "iremos ver a recordação se constituir numa verdadeira duração refletida, num tempo recorrente" (BACHELARD 1988:48), onde o sujeito parte de uma intenção presente ("sem a razão, a memória é incompleta e ineficaz" BACHELARD 1988 p. 49). Para o autor não se pode reviver o passado sem o encadear num tema afetivo necessariamente presente, "e é desse modo que Pierre Janet propõe justamente adicionar ao problema das amnésias o da amnemosínia, ou seja, dar mais importância à ausência de memória do que à perda de memória" (BACHELARD. 1988: 49). Ora, reviver o tempo desaparecido é aprender a inquietude de nossa morte. Desta forma, "só nos recordamos de algo ao proceder a escolhas, ao decantar a vida turva, ao recortar fatos da corrente da vida para neles colocar razões" (BACHELARD. 1988: 51).

É na observação e descrição rítmica da pluralidade, portanto no desenvolvimento da

\footnotetext{
${ }^{24}$ Cf. expressão cunhada por R. CARDOSO DE OLIVEIRA, Sobre o pensamento antropológico, Brasília, Tempo Brasileiro, 1988.

${ }^{25}$ Termo cunhado pelas autoras, inspiradas na obra de Bachelard 1989, 1988, mais especificamente o Capítulo II.
} 
continuidade de uma ação ou estado, apreendida na tensão entre o desejo de transformar e a vontade de continuar, de desencadear o futuro sem as ameaças do presente e os antagonismos do passado, que a dinâmica temporal é traçada no escoamento do tempo apreendido ${ }^{26}$.

Em todas as culturas a noção de duração é uma experiência igualmente individual e coletiva, apontando para a diversidade de representações, sociais e coletivas, das formas de descontinuidades das suas experiências vividas sobre as quais apreendemos a ritmicidade dos seus tempos pensados. Nesta modalidade de se enfocar o fenômeno da memória, o passado não é necessariamente antagônico ao presente, ao contrário, eles superpõem-se ritmicamente e, num processo ondulatório, ao ponto da sua consolidação, deixam a descoberto a matéria de suas lembranças.

Conforme as sábias palavras do mestre: "Nosso passado inteiro também vela atrás de nosso presente" (BACHELARD, 1989). Logo, a memória não se realiza, pois por si mesma, por um impulso íntimo, manifestação de um "eu profundo". A memória é o resultado de uma dada hierarquia de instantes, configurando-se numa dialética da duração, isto é, sobreposição rítmica de um tempo subjetivo e de um tempo do mundo, através da ondulação complexa de ordenações múltiplas que se confirmam umas às outras.

A etnografia da duração, neste sentido, vislumbra o tratamento da memória como conhecimento de si e do mundo, a partir do trabalho de recordar narradas pelos sujeitos, "o que equivale a dizer que não nos recordamos por simples repetição e que devemos compor nosso passado... a humanidade é a narração, não a recitação" (BACHELARD 1988:51).

Desta forma, a etnografia da duração persegue esta obra de recordar, que parte de uma intenção presente, "nenhuma imagem surge sem razão, sem associação de idéias" (BACHELARD. 1989:51), ou seja, sem que ali estejam presentes as estruturas espaçotemporais através das quais a memória se configura como construção de um ato de duração ${ }^{27}$.

\footnotetext{
26 "Mas o que constitui a localização social da memória não é somente uma instrução histórica; é bem mais uma vontade de futuro social. Todo pensamento social está voltado para o futuro. Todas as formas do passado, para criar pensamentos verdadeiramente sociais, devem ser traduzidas na linguagem do futuro humano". (BACHELARD 1988:48).

${ }^{27}$ Incorporando-se as idéias bachelardianas ao pensamento de J. PIAGET, 1978, p.168-169, dir-se-ia que através da dialética da duração, a "inteligência utiliza e prolonga a ação" ao interiorizar o fluxo temporal, logo, tornando as suas operações reversíveis.
} 


\section{BIBLIOGRAFIA}

BACHELARD, Gaston. 1989. La dialectique de la durée. Paris, Quadrige/PUF (1 ed. 1950)

BACHELARD, Gaston. 1988. A dialética da duração. São Paulo, Editora Ática. BERGSON, Henri. 1990. Matéria e memória. Ensaio sobre a relação do corpo com o espírito. São Paulo, Martins Fontes. (1 ed. 1939).

BERGSON, Henri. 1978 “A Evolução criadora”, In; Coleção Os Pensadores, São Paulo, Abril Cultural.

BORELLI, Silvia Helena Simões. 1992 "Memória e temporalidade: diálogo entre Walter Benjamin e Henri Bergson”. In: Revista Margem. Faculdade de Ciências Sociais - PUC - São Paulo. P. 79 a 90.

BOSI, Ecléa. 1987. Memória e sociedade. Lembranças de velhos. São Paulo, Queiroz Ed.ltda. e EDUSP.

CARDOSO DE OLIVEIRA, R. 1988 Sobre o pensamento antropológico, Brasília, Tempo Brasileiro.

DURAND, Gilbert. 1984 Les structures anthropologiques de l'imaginaire. Paris, Dunod. DURAND, Gilbert. 1989. As estruturas antropológicas do imaginário. Lisboa, Editorial Presença.

LEROI-GOURHAN, Andre. 1964 Le Geste et La Parole. Vol. I e II. Paris, Albin Michel. PIAGET, Jean. 1978. Sabedoria e Ilusões da Filosofia. São Paulo, Editora Abril. 